\title{
Espécies de moscas-das-frutas (Tephritidae) obtidas em armadilhas McPhail no Estado da Bahia, Brasil
}

\section{Species of fruit flies (Tephritidae) obtained of McPhail trap in the Bahia State, Brazil}

\author{
Maria A. L. Bittencourt ${ }^{1 *}$; Aline K. W. Cova ${ }^{2}$; Augusto C. M. Silva ${ }^{2}$; \\ Vitória E. S. Silva²; Zuzinaide V. Bomfim²; Elton Lúcio Araújo3; \\ Miguel Francisco de Souza Filho ${ }^{4}$
}

\begin{abstract}
Resumo
O objetivo deste trabalho foi conhecer as espécies de moscas-das-frutas que ocorrem em pomares comerciais em alguns municípios da região sul e extremo-sul do estado da Bahia, Brasil. As moscas-dasfrutas foram capturadas, semanalmente, utilizando-se armadilhas McPhail, tendo como atrativo proteína hidrolisada de milho a 5\%. Foi obtido um total de 257 espécimes fêmeas, pertencentes às espécies: Anastrepha fraterculus (77,4\%), A. sororcula (4,7\%), A. obliqua $(2,7 \%)$, A. zenildae $(0,8 \%)$, A. distincta $(0,4 \%)$, A. consobrina (0,4\%), Anastrepha sp.1 (5,1\%) e Ceratitis capitata $(8,5 \%)$.
\end{abstract}

Palavras-chave: Anastrepha, Ceratitis, biodiversidade, fruticultura.

\begin{abstract}
The objective of this study was to provide knowledge on the species of fruit flies in commercial orchards in counties of the southern and extreme southern regions of the State of Bahia, Brazil. Flies were captured weekly by McPhail traps, using a hydrolyzed corn protein at 5\%, as attractant. A total of 257 female was collected, and the species were identified as: Anastrepha fraterculus $(77.4 \%)$, A sororcula $(4.7 \%), A$. obliqua (2.7\%), A. zenildae (0.8\%), A. distincta (0.4\%), A. consobrina (0.4\%), Anastrepha sp.1 (5.1\%) and Ceratitis capitata $(8.5 \%)$.
\end{abstract}

Key words: Anastrepha, Ceratitis, biodiversity, fruit growing.

\footnotetext{
Departamento de Ciências Agrárias e Ambientais - DCAA, Universidade Estadual de Santa Cruz - UESC, 45.662-000, Ilhéus, BA. E-mail: malbitte@uesc.br.

2 Agrônomos, ex-alunos do curso de Agronomia da UESC .

3 Universidade Federal Rural do Semi-Árido - UFERSA. E-mail: elton@esam.br

4 Instituto Biológico. E-mail: miguelf@biologico.sp.gov.br.

* Autor para correspondência
} 
A região nordeste do Brasil apresenta excelentes condições para se tornar um dos maiores pólos produtivos de frutas tropicais para o mercado mundial, pois seu clima permite a produção de diversas espécies frutíferas, sendo que algumas proporcionam mais de uma safra por ano, principalmente em áreas irrigadas. A incidência de moscas-das-frutas (Diptera: Tephritidae), grupo representativo de pragas que causam severos danos à fruticultura, é um fator de preocupação, acarretando aumentos nos custos de produção, em razão das freqüentes aplicações de inseticidas para seu controle e perdas na produção. Estas pragas são de grande importância não só pelos danos diretos que causam às frutas, como também pela limitação às exportações devido a restrições quarentenárias. $\mathrm{O}$ gênero Anastrepha Schiner ocorre principalmente na região Neotropical, sendo que para o Brasil estão registradas 95 espécies. Outros dois gêneros de moscas-das-frutas de importância econômica e quarentenária estão presentes no país, Ceratitis Macleay que é representado por C. capitata (Wied.) e Bactrocera Macquart por B. carambolae Drew \& Hancock, espécie restrita ao Oiapoque, estado do Amapá (ZUCCHI, 2000b; URAMOTO; WALDER; ZUCCHI, 2004).

Com a expansão da fruticultura na região sul e extremo-sul do estado da Bahia, iniciou-se em 2000 um levantamento das espécies e hospedeiros de moscas-das-frutas na região. Nesse trabalho, realizado nos municípios de Una $\left(15^{\circ} 16^{\prime} \mathrm{S}, 39^{\circ} 04^{\prime}\right.$ W), Eunápolis (16 $\left.{ }^{\circ} 16^{\prime} \mathrm{S}, 39^{\circ} 29^{\prime} \mathrm{W}\right)$, Santa Cruz Cabrália $\left(16^{\circ} 22^{\prime} \mathrm{S}, 39^{\circ} 25^{\prime} \mathrm{W}\right)$ e Porto Seguro (16 $21^{\circ} 1^{\prime}$ $\mathrm{S}, 39^{\circ} 15^{\prime} \mathrm{W}$ ), estão relatadas as espécies que foram obtidas nos meses de outubro a dezembro de 2000.

Foram instaladas 15 armadilhas do tipo McPhail, por município, em pomares comerciais de acerola (Malpighia glabra - Malpighiaceae), araçá-boi (Eugenia stipitata - Myrtaceae), pitanga (Eugenia uniflora - Myrtaceae), goiaba (Psidium guajavaMyrtaceae), maracujá (Passiflora edulis f. flavicarpa - Passifloraceae) e mamão (Carica papaya - Caricaceae). Semanalmente, o atrativo alimentar (proteína hidrolisada a 5\%) era substituído, ocasião na qual os insetos capturados nas armadilhas eram transferidos para recipientes plásticos contendo etanol a $70 \%$ e etiquetados com os dados de coleta. Os recipientes foram levados para o laboratório de Entomologia da Universidade Estadual de Santa Cruz - UESC, onde era realizada a triagem do material coletado; as moscas-das-frutas fêmeas foram acondicionadas em recipientes plásticos, contendo etanol a $70 \%$, devidamente etiquetados para posterior identificação.

A identificação das espécies de Anastrepha foi realizada com o microscópio estereoscópico e microscópio óptico, através do exame do acúleo das fêmeas (ARAÚJO, 1997; SOUZA FILHO, 1999).

Nas áreas estudadas, foram obtidos 257 espécimes fêmeas, pertencentes às espécies: Anastrepha fraterculus (Wied.) (77,4\%), A. sororcula Zucchi (4,7\%), A. obliqua (Macquart) (2,7\%), A. zenildae Zucchi (0,8\%), A. distincta Greene (0,4\%), $A$. consobrina (Loew) (0,4\%), Anastrepha sp.1 (5,1\%) e Ceratitis capitata (8,5\%) (Tabela 1). A espécie A. fraterculus foi a predominante, a exemplo do observado nos levantamentos de tefritídeos realizado por outros pesquisadores em diferentes regiões do Brasil (CASTRO PORTILLA, 2002; GARCIA; CAMPOS; CORSEUIL, 2003; URAMOTO; WALDER; ZUCCHI, 2003; URAMOTO; WALDER; ZUCCHI, 2004; FERRARA et al., 2005). No país, A. fraterculus é a mais polífaga, com registro para 67 espécies de hospedeiros, sendo as espécies de Myrtaceae e Rosaceae os hospedeiros mais atacados (ZUCCHI, 2000a; MALAVASI; MORGANTE; ZUCCHI, 1980).

No município de Una, região sul, não foram coletadas as espécies A. consobrina e C. capitata. Provavelmente a ausência da primeira espécie nas coletas foi devido ao maracujazeiro não estar frutificando no período amostrado, e a ausência da segunda espécie, por não haver plantios de café na região. Na região extremo-sul as espécies Anastrepha sp.1 e A. distincta não foram capturadas, provavelmente em razão da ausência de hospedeiros preferenciais próximo aos locais amostrados. 
Tabela 1. Número total e percentagem de espécimes de moscas-das-frutas capturadas em armadilhas McPhail em municípios da região de Sul e Extremo-sul da Bahia. 2000.

\begin{tabular}{cccccccc}
\hline REGIÃO & A. fraterculus & A. sororcula & A.obliqua & A. zenildae & A. distincta & $\begin{array}{c}\text { A. consobrina } \\
\text { Anastrepha sp1 }\end{array}$ & $\begin{array}{c}\text { Ceratitis } \\
\text { capitata }\end{array}$ \\
\hline $\begin{array}{c}\text { Sul } \\
\text { Extremo-sul }\end{array}$ & 106 & 1 & 6 & 1 & 1 & 0 & 0 \\
$\begin{array}{c}\text { Moscas- } \\
\text { das-frutas }\end{array}$ & 77,4 & 4,7 & 2,7 & 0,8 & 0,4 & 0,4 & 0 \\
\hline
\end{tabular}

\section{Referências}

ARAUJO, E. L. Estudo morfométrico no acúleo de cinco espécies de Anastrepha Schiner, 1868 (Diptera, Tephritidae) do grupo fraterculus. 1997. Dissertação (Mestrado em Agronomia)- Escola Superior de Agricultura "Luiz de Queiroz", Universidade de São Paulo, Piracicaba.

CASTRO PORTILLA, N. E. A acerola (Malpighia punicifolia L., 1762) como hospedeiro de moscas-dasfrutas (Diptera: Tephritidae) no recôncavo da Bahia. 2002. Dissertação (Mestrado em Agronomia)- Escola de Agronomia, Universidade Federal da Bahia, Cruz das Almas.

FERRARA, F. A. A; AGUIAR-MENEZES, E. L.; URAMOTO, K.; MARCO JÚNIOR., P.; SOUZA, S. A. S.; CASSINO, P. C. R. Análise faunística de moscas-das-frutas (Diptera, Tephritidae) da Região Noroeste do estado do Rio de Janeiro. Neotropical Entomology, Londrina, v.34, n.2, p.183-190, 2005.

GARCIA, F. R. M.; CAMPOS, J. V.; CORSEUIL, E. Flutuação populacional de Anastrepha fraterculus (Wiedemann., 1830) (Diptera, Tephritidae) na Região Oeste de Santa Catarina, Brasil. Revista Brasileira de Entomologia, São Paulo, v.47, n.3, p.415-420, 2003.

MALAVASI, A.; MORGANTE, J. S.; ZUCCHI, R. A. Biologia de "moscas-das-frutas" (Diptera: Tephritidae). I. Lista de hospedeiros e ocorrência. Revista Brasileira de Biologia, Rio de Janeiro, v.40, n.1, p.9-16, 1980.
SOUZA FILHO, M. F. Biodiversidade de moscas-dasfrutas (Diptera: Tephritidae) e seus parasitóides (Hymenoptera) em plantas hospedeiras no Estado de São Paulo. 1999. Dissertação (Mestrado) - Escola Superior de Agricultura "Luiz de Queiroz", Universidade de São Paulo, Piracicaba.

URAMOTO, K.; WALDER, J. M. M.; ZUCCHI, R. A. Biodiversidade de moscas-das-frutas do gênero Anastrepha (Diptera, Tephritidae) no campus da ESALQUSP, Piracicaba, São Paulo. Revista Brasileira de Entomologia, Curitiba, v.48, n.3, p.409-414, 2004.

URAMOTO, K; WALDER, J. M. M.; ZUCCHI, R. A. Flutuação populacional de moscas-das-frutas do gênero Anastrepha Schiner, 1868 (Diptera, Tephritidae) no Campus “Luiz de Queiroz", Piracicaba, São Paulo. Arquivos do Instituto Biológico, São Paulo, v.70, n.4, p.459-465, 2003.

ZUCCHI, R. A. Espécies de Anastrepha, sinonímias, plantas hospedeiras e parasitóides. In: MALAVASI, A.; ZUCCHI, R. A. (Ed.) Moscas-das-frutas de importância econômica no Brasil. Ribeirão Preto: Holos, 2000a. p.4148.

ZUCCHI, R. A. Taxonomia. In: MALAVASI, A.; ZUCCHI, R. A. (Ed.). Moscas-das-frutas de importância econômica no Brasil. Ribeirão Preto: Holos, 2000b. p.13-24. 